\title{
B8 - Avaliação de alternativas de filtros para clarificação dA colheita do biorreator no processo produtivo da EPOhr
}

Alvio Figueredo Cardero ${ }^{1 \star}$; Victor Gabriel Abramant de Sousa ${ }^{2}$; Maíra Peixoto Pellegrini ${ }^{3}$; Tiago Pereira dos Santos ${ }^{3}$; Marina Vergne de Almeida ${ }^{3}$; Esther Vinhais Gutierrez ${ }^{3}$; Rodrigo Coelho Ventura Pinto ${ }^{3}$.

1 - Centro de Inmunologia Molecular;

2 - Merck Millipore;

3 - Bio-Manguinhos/Fiocruz.

\section{Introdução:}

A produção da eritropoietina humana recombinante (EPOhr), foco da transferência de tecnologia entre Bio-Manguinhos/Fiocruz e o CIM (Cuba), é baseada no cultivo de células $(\mathrm{CHO})$ em biorreator de tanque agitado de grande escala em perfusão. Neste processo, há uma etapa de clarificação de 2000L diários de colheita, objetivando a redução de particulados, resguardando o processo de purificação. Esta clarificação é feita mediante filtros de profundidade, seguida por filtração de membrana para controle da carga microbiológica.

\section{Objetivo:}

Avaliar diferentes especificações e configurações de filtros de profundidade para a clarificação da colheita do cultivo de células em suspensão para a produção da EPOhr.

\section{Metodologia:}

Três tipos de filtros de profundidade foram testados: camada simples; camada simples com adjuvante de filtração; e múltiplas camadas. As combinações testadas foram: CE20+CE30 (controle); DoHC+A1HC; 20MS; CoHC. Filtros de membranas foram colocados à jusante dos filtros de profundidade (Durapore $0.45+0.22$ ou SHC). Os filtros de profundidade foram testados a uma vazão constante (Pmax), enquanto os de membrana, testados a uma pressão constante (Vmax). Cada cascata de filtração foi testada utilizando $500 \mathrm{~mL}$ de suspensão celular proveniente de um biorreator de $2 \mathrm{~L}$, mimetizando características de uma corrente de colheita em escala industrial. Durante o experimento, foram monitoradas a pressão (transdutor de pressão) e a vazão (balanças) para avaliar a capacidade de filtração e dimensionamento dos filtros. Além disso, foram 
avaliados grau de clarificação, pela análise da turbidez e distribuição de partículas (Scepter), e adsorção do produto de interesse às membranas (ELISA). Resultados:

As maiores capacidades de filtração foram observadas nos filtros CoHC e 20MS que, após extrapolação dos resultados para um volume de colheita de $2000 \mathrm{~L}$, necessitariam de $7 \mathrm{~m}^{2}$, seguido da combinação DoHC+A1HC, com $14 \mathrm{~m}^{2}$. Todas superaram o controle que apresentou necessidade de $20 \mathrm{~m}^{2}$ de superfície filtrante. Contudo, estes resultados são preliminares, pois nenhum dos casos testados alcançou o valor de pressão máxima no experimento, o que demonstraria que os filtros atingiram sua capacidade máxima, permitindo avaliar com maior precisão o seu dimensionamento. Todos os filtros de profundidade alcançaram grau de clarificação apropriado para a aplicação desejada (<10NTU), corroborado pela analise de distribuição de partículas nos clarificados. A avaliação da adsorção indesejada de EPOhr à membrana demonstrou que a combinação $\mathrm{D} 0 \mathrm{HC}+\mathrm{A} 1 \mathrm{HC}$ obteve comportamento similar ao controle, com 35\% de perda do produto (versus $38 \%$ do controle), enquanto a menor perda ocorreu no filtro $20 \mathrm{MS}$, com $21 \%$. Finalmente, o uso do filtro de membrana Express SHC permitiu reduzir a uma só etapa a filtração de redução de carga microbiológica sem perda significativa da capacidade de filtração.

\section{Conclusão:}

Verificou-se que, em termos de capacidade de filtração, clarificação e adsorção de EPOhr, as variantes DoHC+A1HC e 20MS constituem alternativas viáveis para substituir a cascata de filtros utilizada atualmente no processo produtivo (padrão).

Palavras-Chave: Eritropoetina Humana Recombinante, Clarificação, Filtração 